\title{
Relationship between the ABO Blood Group and the COVID-19 Susceptibility
}

Jiao Zhao,"\#, Yan Yang ${ }^{2, \#}$, Hanping Huang ${ }^{3, \#}$, Dong $\mathrm{Li}^{4, \#}$, Dongfeng $\mathrm{Gu}^{1}$, Xiangfeng $\mathrm{Lu}^{5}$, Zheng Zhang ${ }^{2}$, Lei $\mathrm{Liu}^{2}$, Ting $\mathrm{Liu}^{3}$, Yukun Liu ${ }^{6}$, Yunjiao $\mathrm{He}^{1}$, Bin Sun ${ }^{1}$, Meilan Wei $^{1}$, Guangyu Yang ${ }^{7, *}$, Xinghuan Wang, ${ }^{8, *}$ Li Zhang ${ }^{3, *}$ Xiaoyang Zhou ${ }^{4, *}$, Mingzhao Xing ${ }^{1, *}$, Peng George Wang ${ }^{1, *}$

${ }^{1}$ School of Medicine, The Southern University of Science and Technology, Shenzhen, People's Republic of China

${ }^{2}$ National Clinical Research Center for Infectious Diseases, The Second Affiliated Hospital of Southern University of Science and Technology, Shenzhen Third People's

Hospital, Shenzhen, People's Republic of China

${ }^{3}$ Infection Disease Department, Wuhan Jinyintan Hospital, Wuhan, China

${ }^{4}$ Renmin Hospital of Wuhan University, Wuhan 430060, People's Republic of China

${ }^{5}$ Department of Epidemiology, Fuwai Hospital, Chinese Academy of Medical

Sciences and Peking Union Medical College, Beijing, People's Republic of China

${ }^{6}$ School of Statistics, East China Normal University, Shanghai, People's Republic of China

${ }^{7}$ School of Life Sciences and Biotechnology, Shanghai Jiao Tong University, Shanghai, People's Republic of China

${ }^{8}$ Department of Urology, Zhongnan Hospital of Wuhan University, Wuhan, China 
medRxiv preprint doi: https://doi.org/10.1101/2020.03.11.20031096; this version posted March 27, 2020. The copyright holder for this preprint (which was not certified by peer review) is the author/funder, who has granted medRxiv a license to display the preprint in perpetuity. All rights reserved. No reuse allowed without permission.

${ }^{\#}$ These authors are considered as equally contributing first authors.

*Corresponding authors: Yang (yanggy@ sjtu.edu.cn); Wang

(wangxinghuan@whu.edu.cn); Zhang (zhangli080806@163.com); Zhou

(xiaoyangzh@whu.edu.cn); Xing (xingmz@ sustech.edu.cn);Wang

(wangp6@sustech.edu.cn)

Running Title: ABO blood group and COVID-19

Key Words: ABO blood group, coronavirus, SARS-CoV-2, COVID-19, disease susceptibility 


\begin{abstract}
:
The novel coronavirus disease-2019 (COVID-19) has been spreading around the world rapidly and declared as a pandemic by WHO. Here, we compared the ABO blood group distribution in 2,173 patients with COVID-19 confirmed by SARS-CoV-2 test from three hospitals in Wuhan and Shenzhen, China with that in normal people from the corresponding regions. The results showed that blood group A was associated with a higher risk for acquiring COVID-19 compared with non-A blood groups, whereas blood group $\mathrm{O}$ was associated with a lower risk for the infection compared with non-O blood groups. This is the first observation of an association between the ABO blood type and COVID-19. It should be emphasized, however, that this is an early study with limitations. It would be premature to use this study to guide clinical practice at this time, but it should encourage further investigation of the relationship between the ABO blood group and the COVID-19 susceptibility.
\end{abstract}




\section{INTRODUCTION}

The novel coronavirus SARS-CoV-2, causing the new infectious coronavirus disease-2019 (COVID-19), is currently spreading rapidly around the world; it has been recently declared as a pandemic by WHO. Recent clinical observation suggests that patient age, male sex and certain chronic medical conditions (e.g., cardiovascular disease, diabetes, COPD) seem to represent a risk for the infection of SARS-Cov-2 and higher disease severity ${ }^{1}$. There is currently no biological marker known to predict the susceptibility to COVID-19. Landsteiner's ABO blood types are carbohydrate epitopes that are present on the surface of human cells. The antigenic determinants of A and B blood groups are trisaccharide moieties GalNAc $\alpha 1-3-($ Fuc $\alpha 1,2)-G a 1 \beta-$ and Gal $\alpha 1-3-(F u c \alpha 1,2)-G a 1 \beta-$, while O blood group antigen is Fuc $\alpha 1,2-G a l \beta-$. While blood types are genetically inherited, the environment factors can potentially influence which blood types in a population will be passed on more frequently to the next generation. Susceptibility of viral infection has been previously found to be related to $\mathrm{ABO}$ blood group. For example, Norwalk virus and Hepatitis B have clear blood group susceptibility ${ }^{2,3}$. It was also reported that blood group $\mathrm{O}$ individuals were less likely to become infected by SARS coronavirus ${ }^{4}$. Here, we investigated the relationship between the $\mathrm{ABO}$ blood type and the susceptibility to COVID-19 in patients from three hospitals in Wuhan and Shenzhen, China to test if the former may be a biomarker for the latter.

\section{METHODS}


We collected and ABO-typed blood samples from 1,775 patients infected with SARS-CoV-2, including 206 dead cases, at the Jinyintan Hospital in Wuhan, Hubei province, China. Another 113 and 285 patients with COVID-19 were respectively recruited from Renmin Hospital of Wuhan University, Hubei province and Shenzhen Third People's Hospital, Guangdong province, China. The diagnosis of COVID-19 was confirmed by a positive real-time reverse transcriptase polymerase-chain-reaction test of SARS-CoV-2 on nasal and pharyngeal swab specimens from patients. Two recent surveys of $\mathrm{ABO}$ blood group distribution of 3,694 normal people from Wuhan City and 23,386 normal people from Shenzhen City were used as comparison controls for the Wuhan and Shenzhen patients with COVID-19, respectively ${ }^{5-6}$. Statistical analyses were performed using chi-squared test. Data from different hospitals were meta-analyzed using random effects models, with calculation of odds ratio (OR) and 95\% confidence interval (CI). Statistical analyses were performed using SPSS software (version 16.0) and STATA software (version 13).

\section{RESULTS}

The ABO blood group in 3,694 normal people in Wuhan displayed a percentage distribution of $32.16 \%, 24.90 \%, 9.10 \%$ and $33.84 \%$ for $\mathrm{A}, \mathrm{B}, \mathrm{AB}$ and $\mathrm{O}$, respectively, while the 1,775 patients with COVID-19 from Wuhan Jinyintan Hospital showed an $\mathrm{ABO}$ distribution of $37.75 \%, 26.42 \%, 10.03 \%$ and $25.80 \%$ for $\mathrm{A}, \mathrm{B}, \mathrm{AB}$ and $\mathrm{O}$, respectively. The proportion of blood group A in patients with COVID-19 was significantly higher than that in normal people, being $37.75 \%$ in the former vs $32.16 \%$ 
in the later $(P<0.001)$. The proportion of blood group $\mathrm{O}$ in patients with COVID-19 was significantly lower than that in normal people, being $25.80 \%$ in the former vs $33.84 \%$ in the later $(\mathrm{P}<0.001$, Table 1$)$. These results corresponded to a significantly increased risk of blood group A for COVID-19 with an OR of 1.279 (95\% CI 1.136 1.440) and decreased risk of blood group O for COVID-19 with an OR of 0.680 (95\% CI 0.599 0.771, Table 1) in comparison with non-A groups and non-O groups, respectively.

A similar distribution pattern of high-risk blood group A and low-risk blood group O was also observed in the dead patients. Specifically, the proportions of blood groups $\mathrm{A}, \mathrm{B}, \mathrm{AB}$ and $\mathrm{O}$ in the 206 dead patients were $41.26 \%, 24.27 \%, 9.22 \%$ and $25.24 \%$, respectively. Blood group A was associated with a higher risk of death compared with non-A groups, with an OR of $1.482(95 \%$ CI 1.113 1.972, $P=0.008$, Table 1). To the contrary, blood group $\mathrm{O}$ was associated with a lower risk of death compared with non-O groups, with an OR of 0.660 (95\% CI 0.479 0.911, $P=0.014$, Table 1).

We next examined 113 patients with COVID-19 from another hospital in Wuhan City, the Renmin Hospital of Wuhan University, and found a similar risk distribution trend of $\mathrm{ABO}$ blood groups for the infection. Specifically, compared with non-A blood groups, blood group A displayed higher relative risk (OR=1.396; 95\% CI 0.952 2.048) than those observed in patients from Wuhan Jinyintan Hospital, although the associations did not reach statistical significance likely due to the small sample size. Compared with non-O groups, blood group $\mathrm{O}$ were significantly 
associated with a lower risk of infection, with an OR of 0.644 (95\% CI 0.418 0.993, $P=0.045$, Table 1).

The ABO blood group in 23,368 normal people in Shenzhen displayed a percentage distribution of $28.77 \%, 25.14 \%, 7.32 \%$ and $38.77 \%$ for $\mathrm{A}, \mathrm{B}, \mathrm{AB}$ and $\mathrm{O}$, respectively. Analysis of 285 patients with COVID-19 from Shenzhen showed proportions of blood groups $\mathrm{A}, \mathrm{B}, \mathrm{AB}$ and $\mathrm{O}$ to be $28.77 \%, 29.12 \%, 13.68 \%$ and $28.42 \%$, respectively. These results similarly showed a significantly lower risk of infection associated with blood group O (OR, 0.627; 95\% CI 0.484 0.812). These results also showed blood group $\mathrm{AB}$ to have an increased risk of infection (OR, 2.008; 95\% CI 1.427 2.824, Table 1).

Figure 1 shows the estimates of ORs of the risk of $\mathrm{ABO}$ blood groups for COVID-19 on the pooled data from the three hospitals by random effects models. Again, the results showed that blood group A was associated with a significantly higher risk for COVID-19 (OR, 1.21; 95\% CI 1.02 1.43, $P=0.027)$ compared with non-A blood groups, whereas blood group $\mathrm{O}$ was associated with a significantly lower risk for the infection (OR, $0.67 ; 95 \%$ CI $0.60 \sim 0.75, P<0.001)$ compared with non-O blood groups. Compared with other ABO blood groups, AB blood group (OR, 1.48, 95\% CI 0.97 2.24) and B blood group (OR, 1.09, 95\% CI 0.98 1.22) seemed to have a trend of higher risk for infection, but the association did not reach statistical significance.

We next investigated whether patient age and sex might influence the ABO blood group distribution among patients with COVID-19. We used the ABO blood group 
distribution of 3,694 normal people in Wuhan area as control to compare with different age and sex groups. When all patients from Jinyintan Hospital and Renmin Hospital in Wuhan city were combined (1,888 patients in total) and grouped into three age groups $(\leq 40,41-59, \geq 60$ years old $)$, the $\mathrm{ABO}$ blood group distribution was similar among the three age groups (Table $\mathrm{S} 1$ ). The ABO blood group distribution was also similar between male and female patients with COVID-19 (Table S1). These results are consistent with the fact that the distribution of $\mathrm{ABO}$ blood groups is known to have no sex and age predilections. For example, by analyzing the blood type of more than ninety thousands normal people, it was found that the percentage of $\mathrm{A}, \mathrm{B}, \mathrm{AB}$ and O blood types were essentially the same among different age groups and among different sexes. ${ }^{7}$

\section{DISCUSSION}

In this study, we found that $\mathrm{ABO}$ blood groups displayed different association risks for the infection with SARS-CoV-2 resulting in COVID-19. Specifically, blood group A was associated with an increased risk whereas blood group $\mathrm{O}$ was associated with a decreased risk, thus demonstrating that the $\mathrm{ABO}$ blood type is a biomarker for differential susceptibility of COVID-19. These findings are consistent with similar risk patterns of $\mathrm{ABO}$ blood groups for other coronavirus infection found in previous studies. For example, Cheng et al. reported that the SARS-CoV infection susceptibility in Hong Kong was differentiated by the ABO blood group systems ${ }^{4}$. The authors found that compared with non-O blood group hospital staff, blood group 
O hospital staff had a lower chance of getting infected. Patrice et al. found that anti-A antibodies specifically inhibited the adhesion of SARS-CoV S protein-expressing cells to ACE2-expressing cell lines ${ }^{7}$. Given the nucleic acid sequence similarity ${ }^{8}$ and receptor angiotensin-converting enzyme 2 (ACE2) binding similarity between SARS-CoV and SARS-CoV-2 ${ }^{9-11}$, the lower susceptibility of blood group O and higher susceptibility of blood group A for COVID-19 could be linked to the presence of natural anti-blood group antibodies, particularly anti-A antibody, in the blood. This speculation will need direct studies to prove. There may also be other mechanisms underlying the $\mathrm{ABO}$ blood group-differentiated susceptibility for COVID-19 that require further studies to elucidate.

\section{Limitations}

This study has several limitations. 1) The numbers of patients from the Renmin Hospital of Wuhan University and Shenzhen Third People's Hospital were both small. Therefore, they cannot represent a solid replication analysis, although the data from these two hospitals showed similar risk patterns of ABO blood groups. 2) The control population groups used in this study lacked information on the subject age and sex and, therefore, a multivariate analysis to adjust the effect of the two factors was not possible. This, however, may not necessarily be a major issue since the $\mathrm{ABO}$ blood group distribution was similar among different age and sex groups of patients in the present study and in normal population reported previously ${ }^{7}$. 3) Due to incomplete information, the influence of the status of chronic medical conditions, such as 
vascular disease, diabetes mellitus and COPD, could not be adjusted through a multivariate analysis, which could potentially bias the conclusions of the present study since these factors may affect the severity of COVID-19.

\section{Conclusions}

In this novel study, we for the first time report an association between the $\mathrm{ABO}$ blood group and COVID-19 susceptibility, demonstrating the latter to be a biomarker differentiating the former. Specifically, people with blood group A have a higher risk whereas people with blood group O have a lower risk for SARS-Cov-2 infection and COVID-19 severity. If verified by future studies, the findings in the present study would have several potential clinical implications. 1) People with blood group A might need particularly strengthened personal protection to reduce the chance of infection; 2) SARS-CoV-2-infected patients with blood group A might need to receive more vigilant surveillance and aggressive treatment; 3) It might be helpful to introduce $\mathrm{ABO}$ blood typing in the management of SARS-CoV-2 infection and COVID-19.

It should be emphasized, however, that given the above limitations, it would be premature to use this study to guide clinical practice at this time. Large replication studies with complete information should be encouraged to pursue and are needed to verify the present findings. Obviously, people with any blood type all need to exercise the wisdom of careful practice to avoid SARS-CoV-2 infection. 


\section{Author contributions statement}

P.G.W and G.Y.Y conceived, designed and supervised the overall study. P.G.W, M.X, G.Y.Y, L.Z , and X.Y.Z supervised and administered the project. L.Z, H.P.H and T.L collected and verified ABO blood types of patients from Wuhan Jinyintan Hospital. X.Y.Z and D.L collected and verified ABO blood types of patients from Renmin Hospital of Wuhan University. Z.Z, L.L and Y.Y collected and verified ABO blood types of patients from Second Affiliated Hospital, Southern University of Science and Technology. Y.J.H, B.S, M.L.W, X.H.W collected and verified the data. D.F.G, X.F.L, Y.K.L, Z.J, M.X, and P.G.W analyzed the data. P.G.W, J.Z, G.Y.Y and M.X, wrote and revised the paper. All authors read and approved the final manuscript.

\section{PATIENTS AND PUBLIC INVOLVEMENT}

This was a retrospective case series study and no patients were directly involved in the study design, setting the research questions, or the outcome measures directly. No patients were asked to advise on interpretation or writing up of results.

Funding: No funding.

\section{Competing interest statement}

The authors declare that they have no competing financial interests.

\section{Ethical approval}

This study received approval from the Research Ethics Committees of the 
participating institutions, which waivered informed patient consent because the study only involved retrospective review of clinical data and because of the urgent nature of the study to investigate a new serious infections disease.

Patient consent: Waived

Data sharing: No additional data available.

\section{Data Availability Statement}

The data used to support the findings of this study are included within the article. 


\section{Reference}

1. Chen N Zhou M Dong X et al. Epidemiological and clinical characteristics of 99 cases of 2019 novel coronavirus pneumonia in Wuhan, China: a descriptive study. Lancet. 2020; $\quad$ (published online Jan https://doi.org/10.1016/S0140-6736(20)30211-7.

2. Batool Z, Durrani SH, Tariq S. Association Of Abo And Rh Blood Group Types

To Hepatitis B, Hepatitis C, Hiv And Syphilis Infection, A Five Year' Experience In Healthy Blood Donors In A Tertiary Care Hospital. J Ayub Med Coll Abbottabad. 2017 Jan-Mar;29(1):90-92.

3. Lindesmith L, Moe C, Marionneau S, Ruvoen N, Jiang X, Lindblad L, Stewart P, LePendu J, Baric R. Human susceptibility and resistance to Norwalk virus infection.J Nat Med. 2003 May;9(5):548-53. Epub 2003 Apr 14.

4. Cheng Y, Cheng G, Chui CH, Lau FY, Chan PK, Ng MH, Sung JJ, Wong RS. ABO blood group and susceptibility to severe acute respiratory syndrome. JAMA. 2005 Mar 23;293(12):1450-1.

5. Xu P, Xiong Y, Cao K.Distribution of $\mathrm{ABO}$ and RhD blood group among Healthy Han population in Wuhan. J Clin Hematol (China). 2015(28):837. 
6. Chen, C. Distribution of $\mathrm{ABO}$ and $\mathrm{Rh}$ (D) blood group and qualty analysis. Int $\mathrm{J}$ Lab Med, 2010 Jan; 31(1):77-8.

7. Guillon P, Clément M, Sébille V, Rivain JG, Chou CF, Ruvoën-Clouet N, Le Pendu J. Inhibition of the interaction between the SARS-CoV spike protein and its cellular receptor by anti-histo-blood group antibodies. Glycobiology. 2008 Dec;18(12):1085-93.

8. Lu R, Zhao X, Li J, Niu P, Yang B, Wu H, Wang W, Song H, Huang B, Zhu N, Bi Y, Ma X, Zhan F, Wang L, Hu T, Zhou H, Hu Z, Zhou W, Zhao L, Chen J, Meng Y, Wang J, Lin Y, Yuan J, Xie Z, Ma J, Liu WJ, Wang D, Xu W, Holmes EC, Gao GF, Wu G, Chen W, Shi W, Tan W. Genomic characterization and epidemiology of 2019 novel coronavirus: implications for virus origins and receptor binding. Lancet. 2020 Jan 30;. doi: 10.1016/S0140-6736(20)30251-8.

9. Li W, Moore MJ, Vasilieva N, Sui J, Wong SK, Berne MA, Somasundaran M, Sullivan JL, Luzuriaga K, Greenough TC, Choe H, Farzan M. Angiotensin-converting enzyme 2 is a functional receptor for the SARS coronavirus. J Nature. 2003 Nov 27;426(6965):450-4.

10. Hoffmann M, Kleine-Weber H, Krüger N, Müller M, Drosten C, Pöhlmann S, The novel coronavirus 2019 (2019-nCoV) uses the SARS-coronavirus receptor ACE2 
medRxiv preprint doi: https://doi.org/10.1101/2020.03.11.20031096; this version posted March 27, 2020. The copyright holder for this preprint (which was not certified by peer review) is the author/funder, who has granted medRxiv a license to display the preprint in perpetuity. All rights reserved. No reuse allowed without permission.

and the cellular protease TMPRSS2 for entry into target cells. bioRxiv 929042 [Preprint]. 31 January 2020. .doi:10.1101/2020.01.31.929042.

11. Wan Y, Shang J, Graham R, Baric RS, Li F. Receptor recognition by novel coronavirus from Wuhan: An analysis based on decade-long structural studies of SARS. J. Virol. JVI.00127-20 (2020). doi:10.1128/JVI.00127-20pmid:31996437. 
medRxiv preprint doi: https://doi.org/10.1101/2020.03.11.20031096; this version posted March 27, 2020. The copyright holder for this preprint (which was not certified by peer review) is the author/funder, who has granted medRxiv a license to display the preprint in perpetuity.

All rights reserved. No reuse allowed without permission.

Table 1. The ABO blood group distribution in patients with COVID-19 and normal controls.

\begin{tabular}{|c|c|c|c|c|}
\hline & \multicolumn{4}{|c|}{ Blood Group } \\
\hline & A & $\mathrm{B}$ & $\mathrm{AB}$ & $\mathrm{O}$ \\
\hline \multicolumn{5}{|c|}{ Controls (Wuhan Area) } \\
\hline 3694 & $1188(32.16 \%)$ & $920(24.90 \%)$ & $336(9.10 \%)$ & $1250(33.84 \%)$ \\
\hline \multicolumn{5}{|c|}{ Wuhan Jinyintan Hospital } \\
\hline \multicolumn{5}{|l|}{ Patients } \\
\hline 1775 & $670(37.75 \%)$ & $469(26.42 \%)$ & $178(10.03 \%)$ & $458(25.80 \%)$ \\
\hline$\chi^{2}$ & 16.431 & 1.378 & 1.117 & 35.674 \\
\hline$P$ & $<0.001$ & 0.240 & 0.291 & $<0.001$ \\
\hline OR & 1.279 & 1.083 & 1.114 & 0.680 \\
\hline $95 \% C I$ & $1.136 \sim 1.440$ & $0.952 \sim 1.232$ & $0.920 \sim 1.349$ & $0.599 \sim 0.771$ \\
\hline \multicolumn{5}{|l|}{ Deaths } \\
\hline 206 & $85(41.26 \%)$ & $50(24.27 \%)$ & $19(9.22 \%)$ & $52(25.24 \%)$ \\
\hline$\chi^{2}$ & 6.944 & 0.015 & 0.000 & 6.102 \\
\hline$P$ & 0.008 & 0.903 & 1.000 & 0.014 \\
\hline OR & 1.482 & 0.966 & 1.015 & 0.660 \\
\hline $95 \% C I$ & $1.113 \sim 1.972$ & $0.697 \sim 1.340$ & $0.625 \sim 1.649$ & $0.479 \sim 0.911$ \\
\hline \multicolumn{5}{|c|}{ Renmin Hospital of Wuhan University } \\
\hline \multicolumn{4}{|l|}{ patients } & $28(24.78 \%)$ \\
\hline$\chi^{2}$ & 2.601 & 0.318 & 1.815 & 3.640 \\
\hline $\mathrm{P}$ & 0.107 & 0.573 & 0.178 & 0.045 \\
\hline OR & 1.396 & 0.857 & 1.530 & 0.644 \\
\hline $95 \% \mathrm{CI}$ & $0.952 \sim 2.048$ & $0.546 \sim 1.344$ & $0.878 \sim 2.664$ & $0.418 \sim 0.993$ \\
\hline \multicolumn{5}{|c|}{ Controls (Shenzhen area) } \\
\hline 23386 & $6728(28.77 \%)$ & $5880(25.14 \%)$ & $1712(7.32 \%)$ & $9066(38.77 \%)$ \\
\hline \multicolumn{5}{|c|}{ Patients from Shenzhen Third People's Hospital } \\
\hline 285 & $82(28.77 \%)$ & $83(29.12 \%)$ & $39(13.68 \%)$ & $81(28.42 \%)$ \\
\hline$\chi^{2}$ & 0.000 & 2.160 & 15.729 & 12.278 \\
\hline$P$ & 1.000 & 0.142 & $<0.001$ & 0.001 \\
\hline OR & 1.000 & 1.223 & 2.008 & 0.627 \\
\hline $95 \% C I$ & $0.773 \sim 1.294$ & $0.946 \sim 1.582$ & $1.427 \sim 2.824$ & $0.484 \sim 0.812$ \\
\hline
\end{tabular}

$C I$, confidence interval; $\mathrm{OR}$, odds ratio; ${ }^{*} P$ value was calculated by 2 -tailed $\chi 2$ 


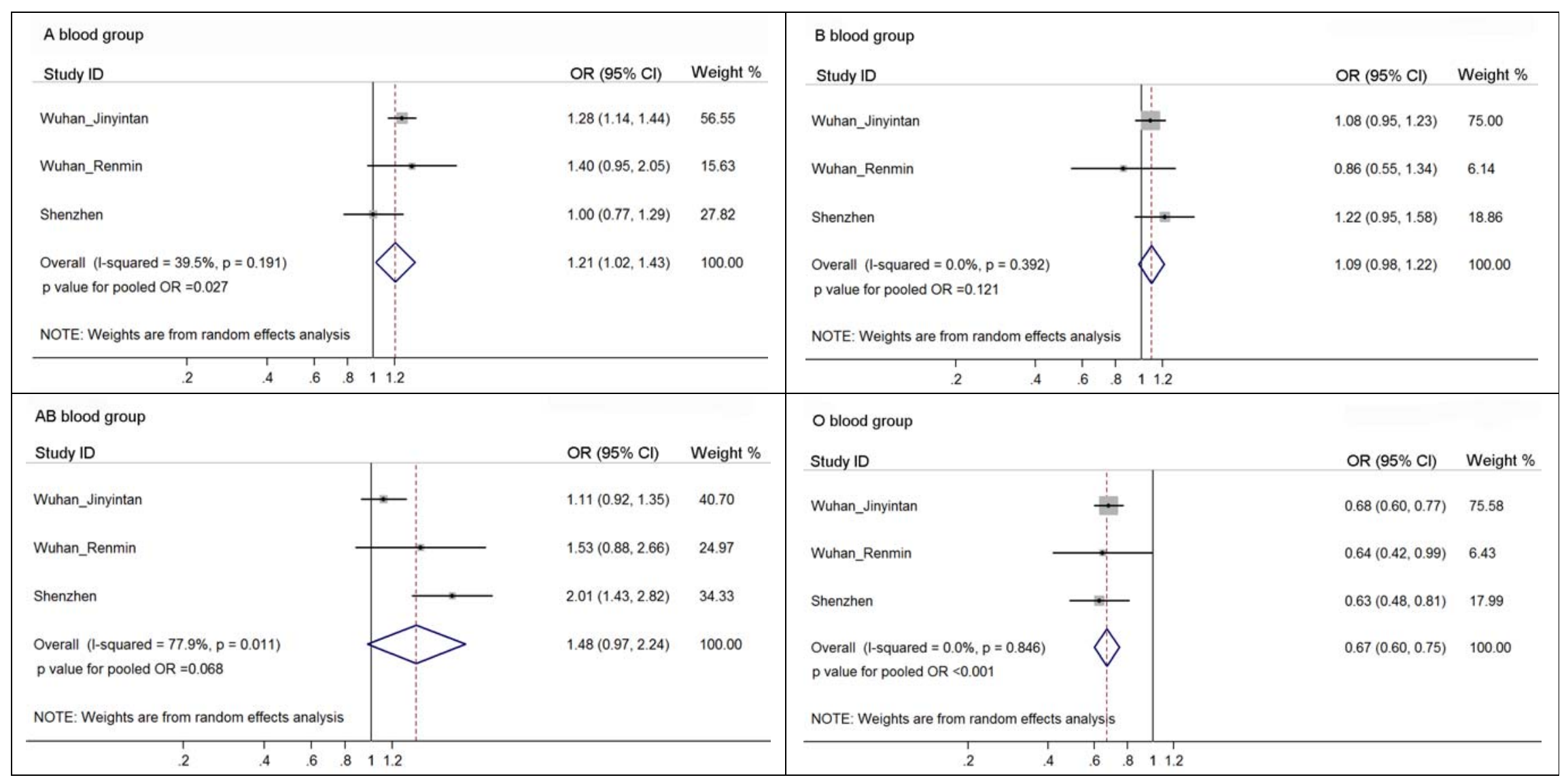

Figure 1. Meta-analysis of the risk of ABO blood groups for COVID-19 in three hospitals.

The X-axis represents the point estimate of odds ratio and corresponding 95\% confidence interval; the Y-axis represents the source of study patients. OR, odds ratio. $C I$, confidence interval. 
Table S1. Influence of age and gender on the ABO blood group distribution in patients with COVID-19 combined from two Wuhan hospitals.

\begin{tabular}{|c|c|c|c|c|}
\hline & \multicolumn{4}{|c|}{ Blood Group } \\
\hline & $\mathrm{A}$ & $\mathrm{B}$ & $\mathrm{AB}$ & $\mathrm{O}$ \\
\hline 3694 Control (Wuhan area) & $1188(32.16 \%)$ & $920(24.90 \%)$ & $336(9.10 \%)$ & $1250(33.84 \%)$ \\
\hline \multicolumn{5}{|l|}{ Wuhan } \\
\hline 1888 patients & $715(37.87 \%)$ & $494(26.17 \%)$ & $193(10.22 \%)$ & $486(25.74 \%)$ \\
\hline$\chi^{2}$ & 17.880 & 0.983 & 1.720 & 37.852 \\
\hline$P$ & $<0.001$ & 0.321 & 0.190 & $<0.001$ \\
\hline OR & 1.286 & 1.069 & 1.138 & 0.678 \\
\hline $95 \% C I$ & $1.145 \sim 1.444$ & $0.941 \sim 1.213$ & $0.944 \sim 1.371$ & $0.599 \sim 0.767$ \\
\hline Less than 40 years & $100(36.63 \%)$ & $78(28.57 \%)$ & $21(7.69 \%)$ & $74(27.11 \%)$ \\
\hline$x^{2}$ & 2.117 & 1.625 & 0.452 & 4.883 \\
\hline$P$ & 0.146 & 0.202 & 0.501 & 0.027 \\
\hline OR & 1.219 & 1.206 & 0.833 & 0.727 \\
\hline $95 \% C I$ & $0.944 \sim 1.575$ & $0.918 \sim 1.585$ & $0.526 \sim 1.318$ & $0.552 \sim 0.958$ \\
\hline Between 41-59 years & $275(39.01 \%)$ & $176(24.96 \%)$ & $71(10.07 \%)$ & $183(25.96 \%)$ \\
\hline$x^{2}$ & 12.197 & $<0.001$ & 0.559 & 16.385 \\
\hline$P$ & $<0.001$ & 1.000 & 0.455 & $<0.001$ \\
\hline OR & 1.349 & 1.003 & 1.119 & 0.685 \\
\hline $95 \% C I$ & $1.142 \sim 1.593$ & $0.833 \sim 1.208$ & $0.855 \sim 1.466$ & $0.572 \sim 0.822$ \\
\hline Over 60 years & $340(37.36 \%)$ & $240(26.37 \%)$ & $101(11.10 \%)$ & $229(25.16 \%)$ \\
\hline$x^{2}$ & 8.679 & 0.759 & 3.181 & 24.797 \\
\hline$P$ & 0.003 & 0.384 & 0.075 & $<0.001$ \\
\hline OR & 1.258 & 1.080 & 1.248 & 0.657 \\
\hline $95 \% C I$ & $1.082 \sim 1.463$ & $0.916 \sim 1.274$ & $0.986 \sim 1.579$ & $0.558 \sim 0.775$ \\
\hline male 1030 & $403(39.13 \%)$ & $275(26.70 \%)$ & $101(9.81 \%)$ & $251(24.37 \%)$ \\
\hline$x^{2}$ & 17.187 & 1.278 & 0.403 & 32.883 \\
\hline$P$ & $<0.001$ & 0.258 & 0.526 & $<0.001$ \\
\hline OR & 1.356 & 1.098 & 1.087 & 0.630 \\
\hline $95 \% C I$ & $1.175 \sim 1.564$ & $0.939 \sim 1.285$ & $0.860 \sim 1.373$ & $0.538 \sim 0.738$ \\
\hline female 858 & $312(36.36 \%)$ & $219(25.52 \%)$ & $92(10.72 \%)$ & $235(27.39 \%)$ \\
\hline$x^{2}$ & 5.379 & 0.111 & 1.976 & 12.884 \\
\hline$P$ & 0.020 & 0.739 & 0.160 & $<0.001$ \\
\hline OR & 1.205 & 1.033 & 1.200 & 0.738 \\
\hline $95 \% C I$ & $1.032 \sim 1.408$ & $0.871 \sim 1.226$ & $0.941 \sim 1.531$ & $0.625 \sim 0.870$ \\
\hline
\end{tabular}

$C I$, confidence interval; $\mathrm{OR}$, odds ratio; ${ }^{*} P$ value was calculated by 2 -tailed $\chi^{2}$ 